\title{
Determination of thermo-physical properties and stability testing of high- temperature phase-change materials for CSP applications
}

\author{
Ming Liu ${ }^{1, *}$, J. Gomez $^{2}$, C.S. Turchi ${ }^{2}$, N. H. S. Tay ${ }^{1}$, W. Saman ${ }^{1}$, F. Bruno ${ }^{1}$ \\ ${ }^{1}$ Barbara Hardy Institute, University of South Australia, \\ Mawson Lakes Boulevard, Mawson Lakes, SA 5095, Australia \\ ${ }^{2}$ Concentrating Solar Power Program, National Renewable Energy Laboratory, \\ 15013 Denver West Parkway, Golden, CO 80401, USA
}

\begin{abstract}
This paper presents the thermo-physical properties and stability testing results of six high-temperature phase-change candidate materials for potential use as a cascaded storage system for concentrating solar power applications. This type of storage is a promising technology because it offers a higher utilization of the possible phase change and a more uniform heat-transfer fluid outlet temperature, compared with the single phase-change material (PCM) storage system. The tested materials were inorganic eutectic PCMs with reported phase-change temperatures between $300^{\circ} \mathrm{C}$ and $600^{\circ} \mathrm{C}$. Four PCMs were made from carbonate salts $\left(\mathrm{Na}_{2} \mathrm{CO}_{3}, \mathrm{~K}_{2} \mathrm{CO}_{3}\right.$, and $\left.\mathrm{Li}_{2} \mathrm{CO}_{3}\right)$ and two from chloride salts $\left(\mathrm{NaCl}, \mathrm{MgCl}_{2}\right.$, and $\left.\mathrm{KCl}\right)$. The phase-change temperature, phase-change enthalpy, and specific heat of these PCMs were measured using a differential scanning calorimeter. Large material samples were tested in an oven subject to multiple melt-freeze cycles. The results showed that the carbonate PCMs have a very high degree of sub-cooling in the initial cycles, which decreased in subsequent cycles. The chloride PCMs have a negligible degree of sub-cooling. There is some disagreement between the measured and reported thermo-physical property values of the tested materials, which demonstrates the uncertainty associated with published property values. One carbonate PCM and one chloride PCM were recommended as promising latent heat storage materials.
\end{abstract}

Keywords: concentrating solar power; phase change materials; thermo-physical properties; thermal stability; thermal cycling; sub-cooling.

1. Introduction

Concentrating solar power (CSP) plants constitute an increasing proportion of future power generation worldwide. CSP systems can incorporate thermal energy storage (TES), which solves the time mismatch between the solar energy supply and electricity demand profiles, and allows for more efficient use of the turbine and other power-block components. The state-of-the-art TES system relies on sensible storage and employs molten salts in cold and hot tanks. Compared to sensible heat storage, latent heat storage using phase-change materials (PCMs) allows large amounts of energy to be stored in relatively small volumes, resulting in a smaller storage system and reduced cost of energy for CSP plants [1,2]. Latent heat storage has been applied in numerous low-temperature applications [3-6] and is quite promising for future hightemperature thermal storage applications $[7,8]$.

\footnotetext{
* Corresponding author. Tel.: +61 (08) 83025132; Fax: +61 (08) 83023380.

E-mail address: ming.liu@unisa.edu.au 
The required PCMs must have a phase-change (melting and freezing) temperature within the desired usage temperature range. For the majority of parabolic trough and solar tower power plants, the operating temperature of the solar field is $290^{\circ}-390^{\circ} \mathrm{C}$ and $290^{\circ}-565^{\circ} \mathrm{C}$, respectively. The currently available heattransfer fluids (HTFs) are synthetic oil, water/steam, and molten nitrate or nitrite salts [9]. Alternative HTFs, such as supercritical carbon dioxide $\left(\mathrm{s}-\mathrm{CO}_{2}\right)$ and other molten salts, are being investigated by research teams worldwide. Higher operating temperatures of over $650^{\circ} \mathrm{C}$ are achievable, and it is known that higher HTF operating temperature generally allows for higher turbine efficiency. Michels and PitzPaal [10] designed and tested a cascaded PCM system using a series of three PCMs spanning the operating temperature range from $290^{\circ} \mathrm{C}$ to $350^{\circ} \mathrm{C}$. The experimental results indicated that the cascaded system offers a higher utilization of the possible phase change compared with the single PCM system. Enormous works have been carried out by Abengoa Solar LLC [11] to develop cascaded arrangement storage systems by using a variety of eutectic salts and metal alloys as PCMs. The cascaded storage system offers a more uniform HTF outlet temperature [10, 12] and higher exergy efficiency [13, 14]. Therefore, it is worthwhile to identify candidate PCMs with melting temperatures in the range of $300^{\circ}-$ $650^{\circ} \mathrm{C}$.

Inorganic salts are promising candidates for high-temperature PCMs because they produce a large enthalpy change without substantial density change during solid-liquid phase transformation. Kenisarin [15] published a comprehensive review on PCMs in the melting temperature range of $120^{\circ}-1000^{\circ} \mathrm{C}$. The PCMs include fluorides, chlorides, bromides, hydroxides, nitrates, carbonates, molybdates, and others. Binary and ternary eutectic compositions based on fluorides and chlorides have high latent heat of fusion; also, the cost of the latter is low. Fluoride salts are less attractive because of their relatively high cost and high corrosion to the containment materials [16]. It has been reported that the melting temperature and heat capacity increase is in the following order: nitrates, chlorides, carbonates, and fluorides [1]. The German Aerospace Centre did intensive research to investigate sodium nitrate as a storage medium in direct steam generation technology [17-19]. Gomez et al. [20] identified three PCMs with melting temperatures near $320^{\circ} \mathrm{C}, 350^{\circ} \mathrm{C}$, and $380^{\circ} \mathrm{C}$. They evaluated the properties of these PCMs and found that the PCMs with chloride anions only were chemically unstable.

The storage capacity of a latent heat storage system is determined by the specific heat of the storage material as well as the enthalpy of the phase change (latent heat of fusion), which can potentially result in a smaller and lower-cost alternative to the currently available sensible storage system. Therefore, it is necessary to investigate the thermo-physical properties of the candidate PCMs because they have a direct impact on the thermal performance and cost analysis of the storage system in the CSP plants. In general, because many of the properties given in the literature are usually calculated rather than experimentally verified values, there is discrepancy between these two values [20]. As an example, the measured latent heat of fusion determined by Gomez et al. [20] is only half of the theoretical value for some eutectic nitrate and chloride PCMs . The discrepancy occurs because the mixtures and eutectics do not exhibit ideal mixing behavior [8]. 
The candidate PCMs should melt congruently and have insignificant sub-cooling; otherwise, the storage capacity of the system will be reduced. Also, good chemical and thermal stability are necessary to ensure a reasonable life span of the storage system, which is another important criterion for the PCM selection. The life span of the storage system for CSP plants is considered to be between 20 and 30 years. However, only limited research exists on the thermal stability of high-temperature PCMs. Laing et al. [18] tested a prototype PCM storage unit filled with sodium nitrate. The operation of 172 cycles (more than 4000 hours) proved there was no change in the melting temperature and no decomposition of the PCM. Shin et al. [16] tested a salt eutectic (32 wt. $\% \mathrm{Li}_{2} \mathrm{CO}_{3}-35 \mathrm{wt} \% \mathrm{~K}_{2} \mathrm{CO}_{3}-33 \mathrm{wt} . \% \mathrm{Na}_{2} \mathrm{CO}_{3}$ ) and found that it exhibits a distinct phase-change temperature $\left(395^{\circ}-397^{\circ} \mathrm{C}\right)$ without phase separation or sub-cooling over 50 thermal cycles, and the corrosion of the salt within the SS316 container was negligible. Petri et al. [21] evaluated four carbonate salts $\left(\mathrm{Li}_{2} \mathrm{CO}_{3}, \mathrm{Na}_{2} \mathrm{CO}_{3}, 52.2\right.$ wt. $\% \mathrm{BaCO}_{3}-47.8$ wt.\% $\mathrm{Na}_{2} \mathrm{CO}_{3}$, and 81.3 wt.\% $\mathrm{Na}_{2} \mathrm{CO}_{3}-18.7$ wt. $\% \mathrm{~K}_{2} \mathrm{CO}_{3}$ ) as PCMs and they cycled those candidates for $13,21,36$, and 38 cycles, respectively. They found that the eutectic salt with 52.2 wt. $\% \mathrm{BaCO}_{3}$ and 47.8 wt. $\% \mathrm{Na}_{2} \mathrm{CO}_{3}$ showed stable performance, but the melting point measured was $30^{\circ} \mathrm{C}$ higher than the published value $\left(686^{\circ} \mathrm{C}\right)$. The salt mixture with 81.3 wt. $\% \mathrm{Na}_{2} \mathrm{CO}_{3}-18.7$ wt. $\% \mathrm{~K}_{2} \mathrm{CO}_{3}$ was not stable and it melted incongruently. When the pure salts $\left(\mathrm{Li}_{2} \mathrm{CO}_{3}\right.$ and $\left.\mathrm{Na}_{2} \mathrm{CO}_{3}\right)$ were tested in sealed containers, they leaked through the weld and fittings.

This paper aims to characterize the thermo-physical properties of six PCM candidates with melting temperatures between $300^{\circ} \mathrm{C}$ and $600^{\circ} \mathrm{C}$. The temperature range was selected to allow for a cascaded PCM storage system to be developed for current and future solar tower power plants. The composition of the carbonate and chloride salt eutectic PCMs was taken from the literature. The properties measured include the phase-change temperature, latent heat of fusion, and solid and liquid specific heat capacities. Also, the thermal stability of the salt eutectics has been examined by repeatedly cycling the candidates between $300^{\circ} \mathrm{C}$ and $600^{\circ} \mathrm{C}$ in a furnace. To our knowledge, this is the first time that the thermo-physical properties of the investigated PCMs have been measured by experiment and their thermal stability evaluated.

2. Materials and methodology

\subsection{Materials}

Table 1 provides the listing of the compositions and thermo-physical properties of the salt mixtures studied. Candidates CA1-CA4 are eutectic mixtures of carbonate salts and $\mathrm{CH} 1$ and $\mathrm{CH} 2$ are eutectic mixtures of chloride salts. The thermo-physical properties of candidate CA1 were obtained by experiment, whereas the properties of the other candidates are calculated values. The individual carbonate and chloride salts were supplied by Alfa Aesar and Sigma Aldrich with purity levels greater than 99\%. The salts were dried in a muffle furnace at $120^{\circ} \mathrm{C}$ for 24 hours. The single dried salts were weighed in a balance with a resolution of $0.1 \mathrm{mg}$ and mixed at a specific ratio as shown in Table 1. Because chloride salts are highly hygroscopic, the weighing and mixing procedures were performed inside a dry glove-box under UHP nitrogen atmosphere. Before performing the differential scanning calorimeter (DSC) test, the samples were placed in a furnace at $120^{\circ} \mathrm{C}$ for 2 hours to remove any moisture absorbed during sample handling and preparation.

Table 1: Composition of candidate PCMs and their melting temperatures $\left(T_{m}\right)$, latent heats of fusion ( $\left.\Delta H\right)$, and solid and liquid specific heats $\left(\mathrm{C}_{\mathrm{p}, \mathrm{s}}\right.$ and $\left.\mathrm{C}_{\mathrm{p}, \mathrm{l}}\right)[15]$. 


\subsection{Methodology}

\subsubsection{Differential scanning calorimeter}

The specific heat capacity and latent heat of fusion and phase-change temperature were evaluated using a DSC (Netzsch DSC 404), which operates according to the heat-flux principle. A sample and a reference are subjected to a controlled temperature program (heating, cooling, or isothermal segment) and the DSC sensor measures the temperature of the sample and the difference between the sample and reference. Then the heat-flow difference between the sample and reference can be determined. To measure the solid and liquid specific heat capacities for the PCM samples, the ASTM E1269-05 standard was followed, in which a sapphire disk with known heat capacity is employed as the reference material.

Before performing the test, the chemical stability of the DSC container materials (aluminum, SS316, aluminum oxide, and graphite) with the PCMs was evaluated in a controlled-atmosphere furnace under UHP nitrogen gas. Aluminum oxide and graphite crucibles with lids were used in the phase-change temperature and enthalpy measurement because they showed good corrosion resistance. In the heatcapacity measurement, graphite crucibles were used to obtain fast heat transfer into the sample due to the high thermal conductivity of the graphite. The analyses were conducted under a constant stream of UHP nitrogen at a flow rate of $20 \mathrm{~mL} / \mathrm{min}$ at a heating/cooling rate of $10 \mathrm{~K} / \mathrm{min}$ for phase-change temperature and enthalpy measurements, and $20 \mathrm{~K} / \mathrm{min}$ for specific-heat capacity measurements. A smaller heating/cooling rate of $5 \mathrm{~K} / \mathrm{min}$ was also employed in the preliminary test, but no obvious discrepancy was found in the results; hence $10 \mathrm{~K} / \mathrm{min}$ was used for the temperature and enthalpy tests. The DSC has a calorimetric data resolution of $0.01 \mu \mathrm{W}$ and a temperature accuracy of $\pm 0.20 \mathrm{~K}$. DSC measurements were repeated four times for carbonate candidates CA1-CA4 and the average values were taken as the results.

Measurement of molten chloride PCMs at high temperatures is difficult because the chloride salts in the liquid state strongly wet the graphite containers. As a result, the salt creeps toward the crucible wall and the salt in the container is thicker near the wall and thinner in the middle. This condition leads to a temperature gradient in the sample that affects the accuracy of the measurement. Therefore, in phasechange temperature and enthalpy measurements, three samples were taken and tested for each chloride candidate, two melt-freeze cycles were carried out for each sample, and the average values were taken as the results.

\subsubsection{Thermal cycling test using high-temperature furnace}

A furnace with a maximum operating temperature of $1200^{\circ} \mathrm{C}$ was used to conduct the stability test (meltfreeze cycling). Generally, the sub-cooling problem is more severe in small samples, such as those used for DSC testing [22]. To avoid this problem and to get more realistic values of the phase-change temperature range, larger PCM samples $(50-150 \mathrm{~g})$ were used in the stability test. The experimental setup in the furnace is presented in Figure 1. The furnace has an internal dimension of $0.25 \mathrm{~m} \times 0.25 \mathrm{~m} \times 0.3 \mathrm{~m}$. Carbonate and chloride PCM samples were contained in SS316L and aluminum oxide crucibles, respectively. Type $\mathrm{K} \mathrm{Omega}^{\mathrm{TM}}$ thermocouples with an accuracy of $\pm 0.75 \%$ were covered with aluminum oxide sheaths to protect the thermocouple from the corrosion of the salt. Then the sheathed thermocouples were inserted into the PCM samples to measure their temperatures during both melting and freezing. The temperature of the oven was controlled at $300^{\circ} \mathrm{C}$ and $600^{\circ} \mathrm{C}$ during the freezing 
and melting processes, respectively. The temperatures inside the PCM samples and the furnace were recorded every 10 seconds by using a data acquisition system. The thermal stability of candidate CA1 as shown in Table 1 was tested by Shin et al. [16] and the eutectic exhibits a distinct phase-change temperature $\left(395^{\circ}-397^{\circ} \mathrm{C}\right)$ without phase separation or sub-cooling over 50 thermal cycles. Therefore, it was deemed unnecessary to include CA1 in this test.

Figure 1: Schematic diagram of the experimental setup for the thermal cycling test in the furnace.

\subsection{DSC analysis}

The software Proteus ${ }^{\circledR}$ from Netzsch was used to measure and evaluate the DSC data. After the measurement, the DSC signals (heat flow) of the sample and the reference under the same controlled temperature program were plotted against temperature. The phase-change temperature (melting and freezing) was taken as the baseline onset. The latent heat of fusion was estimated by the integration of the DSC heat flux under the phase transformation peak. The specific heat capacity of the PCM was evaluated based on the known heat capacity of the sapphire, as shown in Eqn. 1,

$$
C_{p, \text { sample }}=\frac{m_{\text {sapphire }}}{m_{\text {sample }}} \times \frac{D S C_{\text {sample }}-D S C_{\text {baseline }}}{D S C_{\text {sapphire }}-D S C_{\text {baseline }}} \times C_{p \text {,sapphire }}
$$

where $C_{p, \text { sample }}$ and $C_{p \text {,sapphire }}$ are the specific heat capacities of the sample and the sapphire; $m_{\text {sample }}$ and $m_{\text {sapphire }}$ are the masses of the sample and the sapphire; and $D S C_{\text {sample }}, D S C_{\text {sapphire, }}$ and $D S C_{\text {baseline }}$ are the DSC heat flux signals for the sample, sapphire, and baseline measurements, respectively.

3. Results and discussion

3.1 Phase-change temperature and latent heat of fusion

The phase-change temperatures and latent heats of fusion of the PCMs under investigation were evaluated and the results are summarized in Table 2. One sample for each of the candidates CA1-CA4 was tested and each subjected to four melt-freeze cycles. Due to the creeping behavior of the chloride salt on the crucible wall, three samples for candidates $\mathrm{CH} 1$ and $\mathrm{CH} 2$ were tested and each of these subjected to two melt-freeze cycles. The sample weights are listed in Table 2. The thermo-physical properties of CA1 measured in this study are very close to the reported values, which are the experimental values. For the other samples, there is a discrepancy between the measured value and the calculated value, shown in Table 1. For PCMs made from carbonate salts, the freezing temperatures are usually much lower than the melting temperatures, which indicate that those PCMs have high degrees of sub-cooling. Compared to carbonate salts, chloride candidates $\mathrm{CH} 1$ and $\mathrm{CH} 2$ have much smaller degrees of sub-cooling. Subcooling is undesirable because it reduces the usability of PCMs and can also completely prevent heat recovery if too severe [23]. Some PCMs show sub-cooling in the DSC test because of the small amount of sample used [24]. However, they could show no or a small degree of sub-cooling in large-scale plants [24].

Table 2: DSC test results of phase-change temperature and latent heat of fusion $\left(T_{m}\right.$ and $T_{f}$ : melting and freezing temperature; $\Delta \mathbf{H}_{\mathrm{m}}$ and $\Delta \mathbf{H}_{\mathrm{f}}$ : latent heats of melting and freezing). 
Furthermore, the latent heat of solidification (freezing) is $30-60 \mathrm{~J} / \mathrm{g}$ less than the latent heat in the melting process for carbonate candidates CA1, CA3, and CA4. In contrast, $\Delta \mathrm{H}_{\mathrm{f}}$ and $\Delta \mathrm{H}_{\mathrm{m}}$ values differ by only 1 - $14 \mathrm{~J} / \mathrm{g}$ for chloride candidates $\mathrm{CH} 1$ and $\mathrm{CH} 2$ and carbonate candidate $\mathrm{CA} 2$. Figure 2 - Figure 4 show the DSC curves of samples CA1, CA3, and CA4 for four consecutive melt-freeze cycles. In addition to the major exothermic phase change where the materials release most of their latent heat of solidification there is another noticeable exothermic phase change (shown in the circles in Figures 2-4) that occurs mostly at $100 \mathrm{~K}$ below the melting temperature of candidates CA1, CA3, and CA4 during heating. During this process, the absorbed energy is roughly equal to the difference of the phase-change enthalpy measured in the melting and freezing processes. For candidate CA1, this process sometimes happens just before the melting process starts, as presented in Figure 2. In addition, the measured melting temperature of CA4 is $422.5^{\circ} \mathrm{C}$, which is dramatically lower than the reported value $\left(580^{\circ} \mathrm{C}\right)$ [15].

Figure 2: DSC curves of CA1 $\left(32 \mathrm{Li}_{2} \mathrm{CO}_{3}-35 \mathrm{~K}_{2} \mathrm{CO}_{3}-33 \mathrm{Na}_{2} \mathrm{CO}_{3}\right.$, wt. \%) for four melt-freeze cycles.

Figure 3: DSC curves of $\mathrm{CA3}\left(35 \mathrm{Li}_{2} \mathrm{CO}_{3}-65 \mathrm{~K}_{2} \mathrm{CO}_{3}\right.$, wt. \%) for four melt-freeze cycles.

Figure 4: DSC curves of CA4 $\left(22 \mathrm{Li}_{2} \mathrm{CO}_{3}-62 \mathrm{~K}_{2} \mathrm{CO}_{3}-16 \mathrm{Na}_{2} \mathrm{CO}_{3}\right.$, wt. \%) for four melt-freeze cycles.

Figure 5: DSC curves of $\mathrm{CA2}\left(28.5 \mathrm{Li}_{2} \mathrm{CO}_{3}-71.5 \mathrm{~K}_{2} \mathrm{CO}_{3}\right.$, wt. \%) for four melt-freeze cycles.

Figure 5 shows the DSC curves of sample CA2 for four consecutive melt-freeze cycles. The melting processes for cycles 1-4 are not consistent, in which the phase-change temperatures and latent heats of fusion vary randomly from $468.7^{\circ} \mathrm{C}$ to $500.4^{\circ} \mathrm{C}$ and $234.1 \mathrm{~J} / \mathrm{g}$ to $265.5 \mathrm{~J} / \mathrm{g}$, respectively. However, all of the freezing processes occurred at a similarly sharp and narrow temperature range, and the measured freezing temperature and latent heat of fusion are $440.4 \pm 3.0^{\circ} \mathrm{C}$ and $233.3 \pm 1.5 \mathrm{~J} / \mathrm{g}$, respectively. The average values of the latent heats obtained during both melting and freezing processes are quite similar.

The measured phase-change temperatures of candidates $\mathrm{CH} 1$ and $\mathrm{CH} 2$ are slightly lower than the reported values [15], but the measured enthalpies are around half of the reported values. Gomez [25] tested three eutectic PCMs (34.81 wt.\% $\mathrm{NaCl}-32.29$ wt.\% $\mathrm{KCl}-32.9$ wt.\% LiCl, 80.69 wt.\% $\mathrm{KNO}_{3}-11.87$ wt.\% $\mathrm{KBr}-7.44$ wt. $\% \mathrm{KCl}$, and 60 wt. $\% \mathrm{MgCl}_{2}-20.4$ wt. $\% \mathrm{KCl}-19.6 \mathrm{wt} . \% \mathrm{NaCl}$ ) using the DSC and found that the latent heat of fusion was almost half or less than the expected values from the literature.

\subsection{Specific heat capacity}

The specific heat capacity curves for carbonate PCM samples in the solid and liquid states, excluding phase transition, are shown in Figure 6. Generally, the specific heat capacities of the solid carbonate PCMs increase slightly as temperature rises, and they are relatively constant in the liquid state. The average specific heat capacities on the solid and liquid states are listed in Table 3. The results for candidates CA1 and CA3 were quite close to the previously reported values [15]. There is a sizeable 
discrepancy between the measured and reported values for CA4. However, it is believed that the result from this study is more reliable because the specific heat capacities of all the other carbonate eutectics are in a similar range.

Because of the creeping problem of the liquid chloride salt, only the specific heat capacities for solid chloride PCM samples are shown in Figure 7 and Table 3. The eutectic of $\mathrm{MgCl}_{2}$ and $\mathrm{NaCl}(\mathrm{CH} 1)$ has a slightly increased specific heat capacity with temperature, and the eutectic of $\mathrm{MgCl}_{2}$ and $\mathrm{KCl}(\mathrm{CH} 2)$ has an approximately constant specific heat capacity between 0.70 and $0.75 \mathrm{~J} /(\mathrm{g} \cdot \mathrm{K})$ over the measured temperature range.

Figure 6: Results of specific heat capacities for carbonate PCM candidates in the solid and liquid phases.

Figure 7: Results of specific heat capacities for chloride PCM candidates in the solid phase.

Table 3: Averaged results of DSC specific heat capacities of PCM candidates $\left(C_{p, s}\right.$ and $C_{p, l}$ : solid and liquid specific heat).

\subsection{Thermal cycling stability}

As previously mentioned, the chemical and thermal stabilities of a PCM are important criteria for material selection. Any degradation of the PCM would decrease its latent heat of fusion and alter its phase-change temperature range [22], which will reduce the life span of the storage system and reduce the efficiency of the power block if the phase-change temperature drops.

- Carbonate PCM candidates

Candidates CA2-CA4 (about 150 g) have undergone 100 melt-freeze cycles. Figures 8-10 show the temperature profiles of CA2-CA4 during different melt-freeze cycles, respectively. The profiles present the typical three stages of PCM melting and freezing [26]. A sub-cooling phenomenon was observed in all the carbonate samples, and it is more severe in samples CA2 and CA3, which can reach as high as 35 $\mathrm{K}$. This value is smaller compared to that in the small-sample DSC test. The aluminum oxide sheath in sample CA2 was broken after 50 cycles; therefore, the temperature profile after 50 cycles is not presented in Figure 8. In sample CA2, the sub-cooling is nearly $35 \mathrm{~K}$ in the first and tenth cycles. It reduces to $25 \mathrm{~K}$ at the $30^{\text {th }}$ cycle and further reduces to $16 \mathrm{~K}$ at the $50^{\text {th }}$ cycle.

Figure 8: Temperature of sample $\mathrm{CA2}\left(28.5 \mathrm{Li}_{2} \mathrm{CO}_{3}-71.5 \mathrm{~K}_{2} \mathrm{CO}_{3}\right.$, wt. \%) during: (a) melting process and (b) freezing process.

In sample CA3, the sub-cooling occurs frequently in the first 70 cycles. However, sub-cooling was rarely detected afterwards. As shown in Figure 9a, the temperature profiles for the first and the one-hundredth cycles are quite close in the melting process and it does not show any degradation. The freezing 
temperature where sub-cooling occurs is about $30 \mathrm{~K}$ higher than that without sub-cooling. Further research is warranted to investigate the causes of this phenomenon.

Figure 9: Temperature of sample $\mathrm{CA3}\left(35 \mathrm{Li}_{2} \mathrm{CO}_{3}-65 \mathrm{~K}_{2} \mathrm{CO}_{3}\right.$, wt. \%) during: (a) melting process and (b) freezing process.

Figure 10a shows that sample CA4 melts over a very wide temperature range, which is also proved by the DSC results in Figure 4. Also, as the number of cycles increases, the range of the melting temperature increases. After 20 cycles, the phase-change phenomenon becomes unnoticeable as the temperature where melting commences cannot be clearly seen. Figure 10b shows that the temperature profile shows a plateau at around $420^{\circ} \mathrm{C}$ when the sample CA4 experienced the first solidification. As the number of cycles increases, the solidification temperature range becomes wide.

Figure 10: Temperature of sample $\mathrm{CA} 4\left(22 \mathrm{Li}_{2} \mathrm{CO}_{3}-62 \mathrm{~K}_{2} \mathrm{CO}_{3}-16 \mathrm{Na}_{2} \mathrm{CO}_{3}\right.$, wt.\%) during: (a) melting process and (b) freezing process.

- Chloride PCM candidates

Chloride PCMs (candidates $\mathrm{CH} 1$ and $\mathrm{CH} 2$, about $50 \mathrm{~g}$ ) were subjected to 40 melt-freeze cycles. Sample $\mathrm{CH} 2$ started to creep out of the container from the beginning of the tests and the weight of the sample gradually decreased. After 40 cycles, almost all of the salt in sample $\mathrm{CH} 2$ was found to creep out. This trait may be caused by the high wettability of aluminum oxide by liquid chloride salts and the high partial vapor pressure of the chlorides. It was observed that the salt in sample $\mathrm{CH} 1$ creeps slightly along the container wall after 40 cycles; hence, the test was terminated. Figure 11 shows the temperature profiles of sample $\mathrm{CH} 1$ during different melt-freeze cycles. The temperature and time period of the phase-change obtained in different cycles are quite close to each other. Therefore, no degradation on the phase-change temperature and the latent heat was shown after 40 cycles. Furthermore, the degree of sub-cooling is very small, i.e., a maximum of two degrees Celsius.

Figure 11: Temperature of sample $\mathrm{CH1}\left(52 \mathrm{MgCl}_{2}-48 \mathrm{NaCl}\right.$, wt.\%) during: (a) melting process and (b) freezing process. 


\section{Conclusions}

For carbonate PCMs, in general, the phase change occurs in a wider temperature range during melting than in freezing. With the DSC test results, it is quite common for the exothermic phase change to happen before the substantial melting process, and the latent heat of fusion measured in the solidification is less than that measured in the melting due to this exothermic process. However, the same transformation was not observed in the stability test where larger samples were employed (50 and $150 \mathrm{~g}$ ). This phenomenon will be investigated in the future. Furthermore, the degree of sub-cooling presented in the stability test was much less than that in the DSC test (sample size: $10-15 \mathrm{mg}$ ) and it is significantly reduced after a number of cycles.

Compared with carbonate PCMs, the measurement of molten chloride salts at high temperatures is difficult because of the tendency of the salts to creep up the vessel walls, which may result in an inaccurate liquid specific heat capacity. The sub-cooling phenomenon of the evaluated chloride candidates is negligible. In addition, it is recommended that researchers handle the chloride PCMs in sealed containers in future tests.

\section{- $\quad$ Candidate CA1 $\left(32 \mathrm{Li}_{2} \mathrm{CO}_{3}-35 \mathrm{~K}_{2} \mathrm{CO}_{3}-33 \mathrm{Na}_{2} \mathrm{CO}_{3}\right.$, wt.\%)}

The melting temperature, the latent heat of fusion, and the specific heat capacity of this PCM were measured experimentally by previous researchers, and the results agree closely with those obtained by the DSC test in this work.

- $\quad$ Candidate CA2 $\left(28.5 \mathrm{Li}_{2} \mathrm{CO}_{3}-71.5 \mathrm{~K}_{2} \mathrm{CO}_{3}\right.$, wt.\%)

The melting temperature and latent heat of fusion measured in this study were found to be $479.9^{\circ} \mathrm{C}$ and $234.4 \mathrm{~J} / \mathrm{g}$, which is $18^{\circ} \mathrm{C}$ and $82 \mathrm{~J} / \mathrm{g}$ below the reported values [15], respectively. The latent heats of fusion obtained in both melting and solidification are quite close to each other. This PCM has a very high degree of sub-cooling initially, and it drops about $20^{\circ} \mathrm{C}$ to $16^{\circ} \mathrm{C}$ after 50 melt-freeze cycles.

- $\quad$ Candidate $\mathrm{CA} 3\left(35 \mathrm{Li}_{2} \mathrm{CO}_{3}-65 \mathrm{~K}_{2} \mathrm{CO}_{3}\right.$, wt.\%)

The melting temperature and the specific heat capacity estimated by the DSC in this study are in good agreement with the reported values, whereas the measured latent heat of fusion was found to be $48.8 \mathrm{~J} / \mathrm{g}$ less than the published one. The sub-cooling is $58.6 \mathrm{~K}$ in the DSC result. The sub-cooling is $35 \mathrm{~K}$ at the beginning of the stability test and occurs very infrequently after 70 melt-freeze cycles. However, the freezing temperature without sub-cooling is about $30 \mathrm{~K}$ less than that with sub-cooling, which will reduce the exergy efficiency of the storage system.

\section{- Candidate CA4 $\left(22 \mathrm{Li}_{2} \mathrm{CO}_{3}-62 \mathrm{~K}_{2} \mathrm{CO}_{3}-16 \mathrm{Na}_{2} \mathrm{CO}_{3}\right.$, wt.\%)}

There is considerable discrepancy between the measured and reported phase-change temperature and specific heat capacity. The reported melting temperature is $580^{\circ} \mathrm{C}$, whereas in this study the melting process occurs in a temperature range of about $390^{\circ}-450^{\circ} \mathrm{C}$, which is determined by both the DSC and stability tests. The measured specific heat capacity is about $25 \%$ less than the reported values. However, it is believed that the values obtained in this study are more reliable because they are in the same range as the other carbonate candidates. Candidate CA4 is less attractive as a PCM because: (1) the energy 
absorbed in the melting process is not totally recovered in the freezing process and the difference is above $60 \mathrm{~J} / \mathrm{g}$, and (2) the phase-change phenomenon becomes unnoticeable after 20 melt-freeze cycles.

- Candidate $\mathrm{CH} 1$ and $\mathrm{CH} 2\left(52 \mathrm{MgCl}_{2}-48 \mathrm{NaCl}\right.$ and $64 \mathrm{MgCl}_{2}-36 \mathrm{KCl}$, wt.\%)

The measured phase-change temperatures are slightly lower than the reported values, but the measured phase-change enthalpies are only about half of the values in the literature. No noticeable change has been observed on the phase-change temperature and phase-change time during the 40 melt-freeze cycles for CH1.

Overall, it may be concluded from this study that the published thermo-physical properties- e.g., phasechange temperature, latent heat of fusion, and specific heat capacity - are not always reliable because they are usually calculated values rather than experimental results. This study revealed that there is sometimes a significant discrepancy between the calculated and experimental values. Therefore, it is important to verify the properties of the PCM to be able to accurately design the phase-change thermal storage system. Candidates CA1 (32 $\mathrm{Li}_{2} \mathrm{CO}_{3}-35 \mathrm{~K}_{2} \mathrm{CO}_{3}-33 \mathrm{Na}_{2} \mathrm{CO}_{3}$, wt.\%) and $\mathrm{CH} 1\left(52 \mathrm{MgCl}_{2}-48 \mathrm{NaCl}\right.$, wt.\%) are very promising for use as PCMs in high-temperature applications. Candidates $\mathrm{CA} 2\left(28.5 \mathrm{Li}_{2} \mathrm{CO}_{3}-71.5 \mathrm{~K}_{2} \mathrm{CO}_{3}\right.$, wt.\%) and $\mathrm{CA} 3\left(35 \mathrm{Li}_{2} \mathrm{CO}_{3}-65 \mathrm{~K}_{2} \mathrm{CO}_{3}\right.$, wt.\%) can potentially be used as PCMs, but further investigations are needed to understand the discrepancy in the freezing temperatures with and without sub-cooling. Furthermore, multiple melt-freeze cycling tests with larger quantities of the salt mixtures provide a quite important supplementary check on the data obtained from the small quantity samples typically used in the DSC measurements. Other issues, e.g. corrosion between the PCM and containment material and the decomposition behavior of the PCM at the operating temperature of the CSP plant, have to be examined to identify the full potential use of the candidate PCM.

\section{Acknowledgements}

The work at NREL was financially supported by the U.S. Department of Energy under Contract No. DEAC36-08-GO28308. M. Liu and N.H.S. Tay are funded through individual fellowships provided by the Australian Government, through the Australian Renewable Energy Agency (ARENA). This research was

performed as part of the Australian Solar Thermal Research Initiative (ASTRI), a project supported by the Australian Government, through ARENA. 


\section{References}

[1] A. Hoshi, D.R. Mills, A. Bittar, T.S. Saitoh, Screening of high melting point phase change materials (PCM) in solar thermal concentrating technology based on CLFR, Solar Energy, 79 (2005) 332-339.

[2] A. Mathur, R. Kasetty, J. Oxley, J. Mendez, K. Nithyanandam, Using Encapsulated Phase Change Salts for Concentrated Solar Power Plant, Energy Procedia, 49 (2014) 908-915.

[3] H. Mehling, L.F. Cabeza, Heat and cold storage with PCM - an up to date introduction into basics and applications, Springer, Berlin, Germany, 2008.

[4] B. Zalba, J.M. Marín, L.F. Cabeza, H. Mehling, Review on thermal energy storage with phase change: materials, heat transfer analysis and applications, Applied Thermal Engineering, 23 (2003) 251-283.

[5] M. Liu, W. Saman, F. Bruno, Development of a novel refrigeration system for refrigerated trucks incorporating phase change material, Applied Energy, 92 (2012) 336-342.

[6] M.M. Farid, A.M. Khudhair, S.A.K. Razack, S. Al-Hallaj, A review on phase change energy storage: materials and applications, Energy Conversion and Management, 45 (2004) 1597-1615.

[7] M. Liu, W. Saman, F. Bruno, Review on storage materials and thermal performance enhancement techniques for high temperature phase change thermal storage systems, Renewable and Sustainable Energy Reviews, 16 (2012) 2118-2132.

[8] S. Kuravi, J. Trahan, D.Y. Goswami, M.M. Rahman, E.K. Stefanakos, Thermal energy storage technologies and systems for concentrating solar power plants, Progress in Energy and Combustion Science, (2013).

[9] M. Liu, M. Belusko, N.H. Steven Tay, F. Bruno, Impact of the heat transfer fluid in a flat plate phase change thermal storage unit for concentrated solar tower plants, Solar Energy, 101 (2014) 220-231.

[10] H. Michels, R. Pitz-Paal, Cascaded latent heat storage for parabolic trough solar power plants, Solar Energy, 81 (2007) 829-837.

[11] K. Gawlik, Reducing the Cost of Thermal Energy Storage for Parabolic Trough Solar Power Plants in, Abengoa Solar LLC, 2013.

[12] R.V. Seeniraj, N. Lakshmi Narasimhan, Performance enhancement of a solar dynamic LHTS module having both fins and multiple PCMs, Solar Energy, 82 (2008) 535-542.

[13] S. Aceves-Saborio, H. Nakamura, G.M. Reistad, Optimum efficiencies and phase change temperatures in latent heat storage systems, Journal of Energy Resources Technology, 116 (1994) 79-86.

[14] R. Domanski, G. Fellah, Exergy analysis for the evaluation of a thermal storage system employing PCMS with different melting temperatures, Applied Thermal Engineering, 16 (1996) 907-919.

[15] M.M. Kenisarin, High-temperature phase change materials for thermal energy storage, Renewable and Sustainable Energy Reviews, 14 (2010) 955-970.

[16] B.C. Shin, S.D. Kim, W.-H. Park, Ternary carbonate eutectic (lithium, sodium and potassium carbonates) for latent heat storage medium, Solar Energy Materials, 21 (1990) 81-90.

[17] T. Bauer, D. Laing, U. Kroner, R. Tamme, Sodium nitrate for high temperature latent heat storage, the 11th International Conference on Thermal Energy Storage, Stockholm, Sweden, 2009.

[18] D. Laing, T. Bauer, W.-D. Steinmann, D. Lehmann, Advanced high temperature latent heat storage system - design and test results, The 11th International Conference on Thermal Energy Storage, Stockholm, Sweden, 2009.

[19] D. Laing, C. Bahl, T. Bauer, D. Lehmann, W.-D. Steinmann, Thermal energy storage for direct steam generation, Solar Energy, 85 (2011) 627-633.

[20] J. Gomez, G.C. Glatzmaier, A. Starace, C. Turchi, J. Ortega, High temperature phase change materials for thermal energy storage applications, SolarPACES, Granada, Spain, 2011.

[21] R. Petri, T. Clarr, L. Marianowski, Evaluation of molten carbonates as latent heat thermal energy storage materials., 14th Intersociety Energy Conversion Engineering Conference, Boston, Massachusetts, 1979. 
[22] E. Oró, C. Barreneche, M.M. Farid, L.F. Cabeza, Experimental study on the selection of phase change materials for low temperature applications, Renewable Energy, 57 (2013) 130-136.

[23] G.A. Lane, Phase change materials for energy storage nucleation to prevent supercooling, Solar Energy Materials and Solar Cells, 27 (1992) 135-160.

[24] A. Gil, E. Oró, G. Peiró, S. Álvarez, L.F. Cabeza, Material selection and testing for thermal energy storage in solar cooling, Renewable Energy, 57 (2013) 366-371.

[25] J.C. Gomez, High-temperature phase change materials (PCM) candidates for thermal energy storage (TES) applications, in, National Renewable Energy Laboratory 2011.

[26] M. Liu, W. Saman, F. Bruno, Validation of a mathematical model for encapsulated phase change material flat slabs for cooling applications, Applied Thermal Engineering, 31 (2011) 2340-2347.

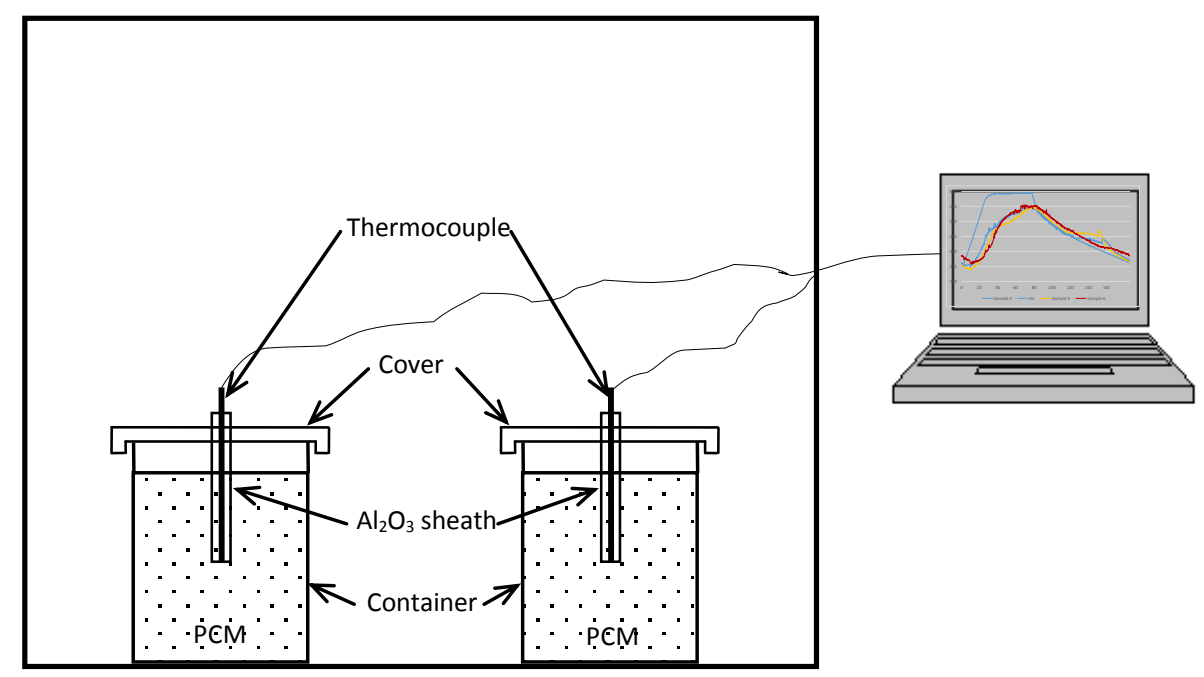




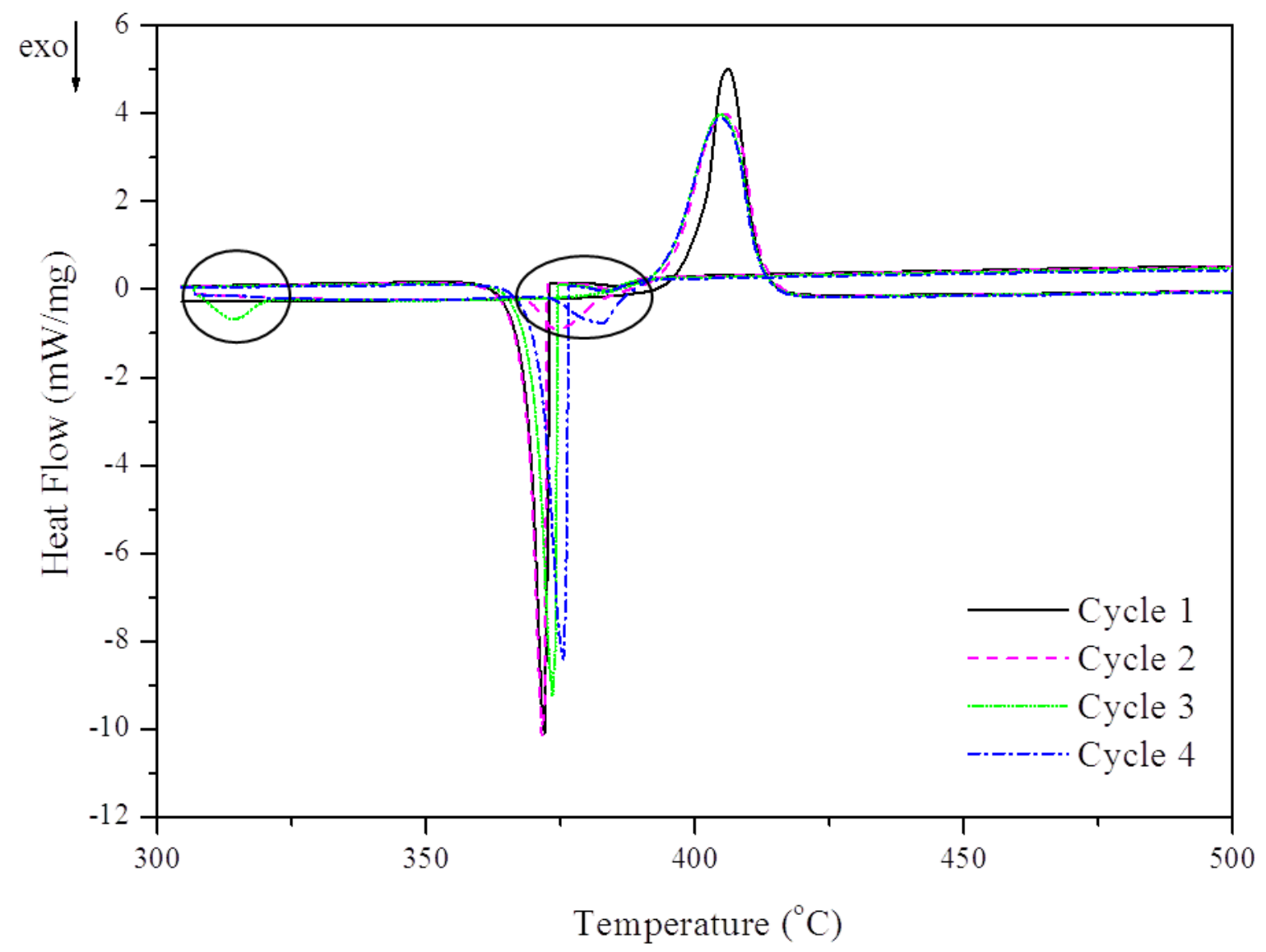




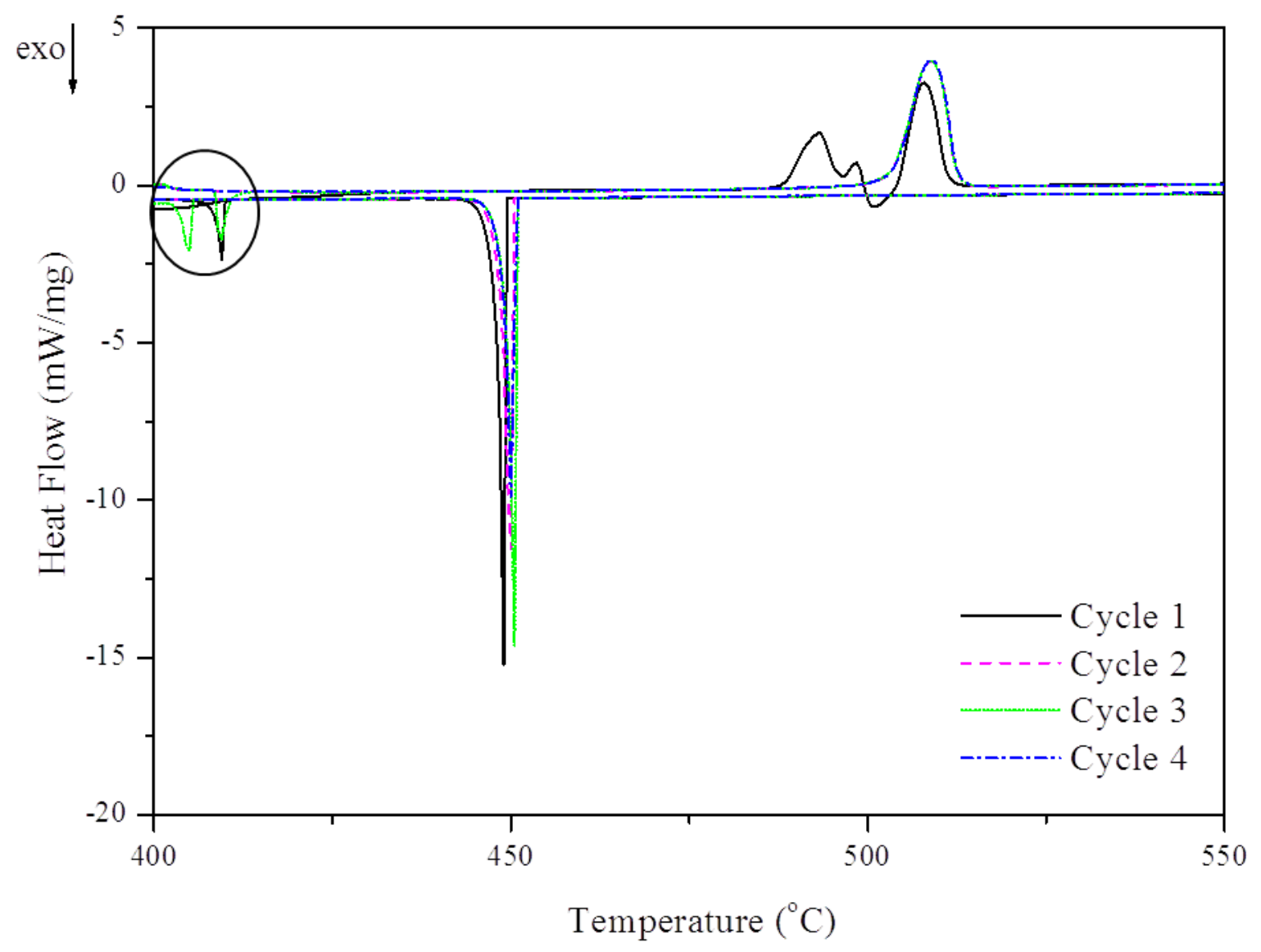




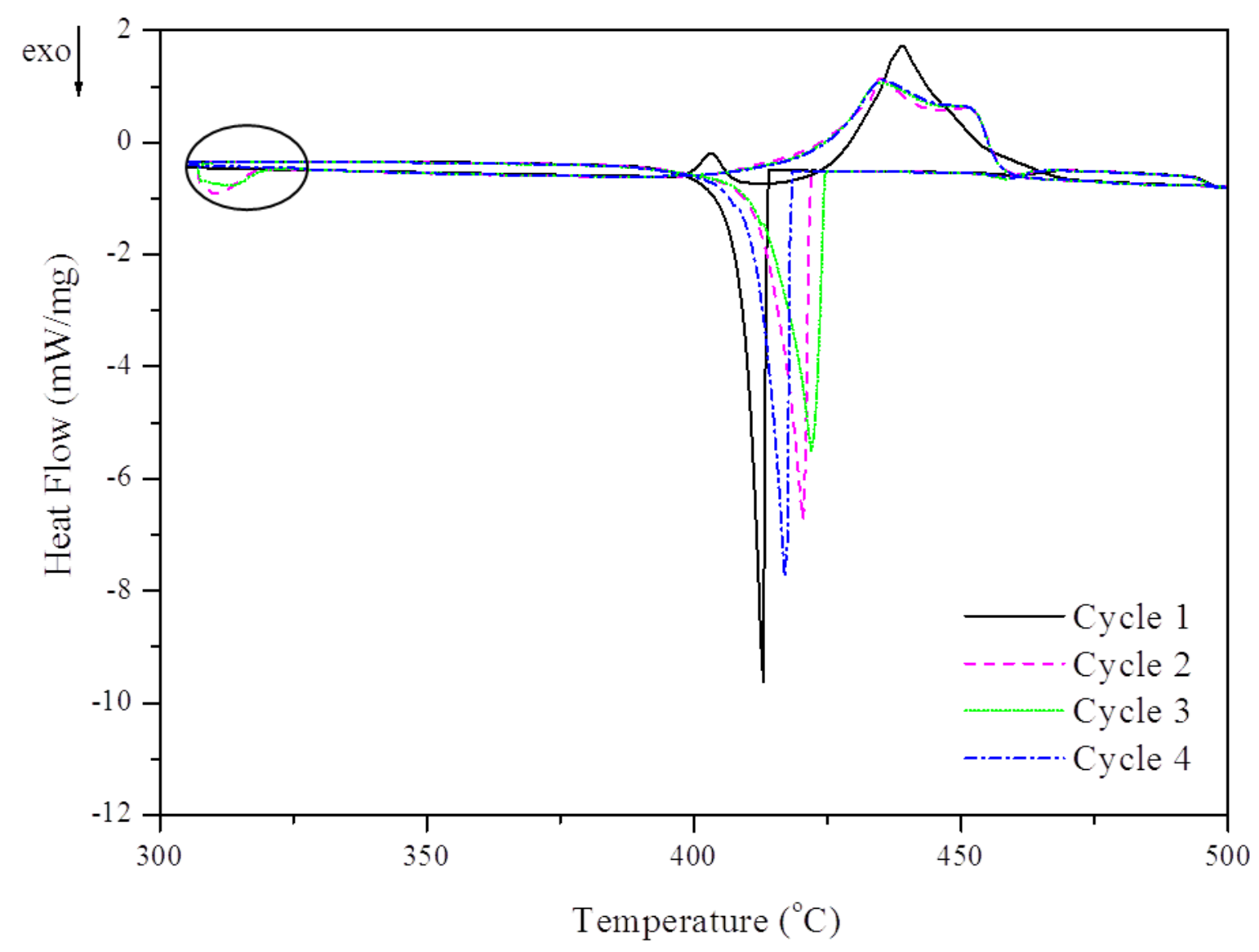




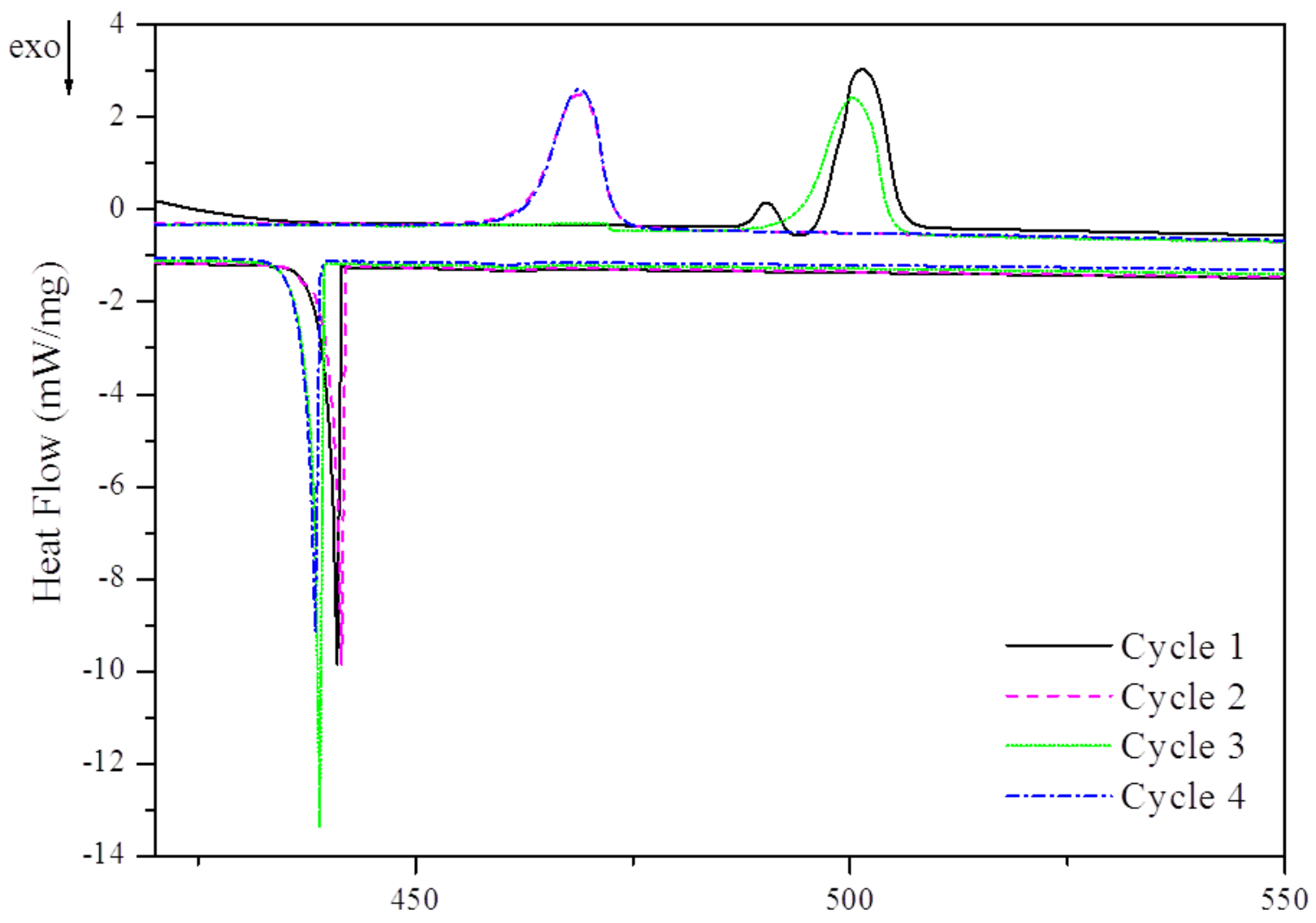

Temperature $\left({ }^{\circ} \mathrm{C}\right)$

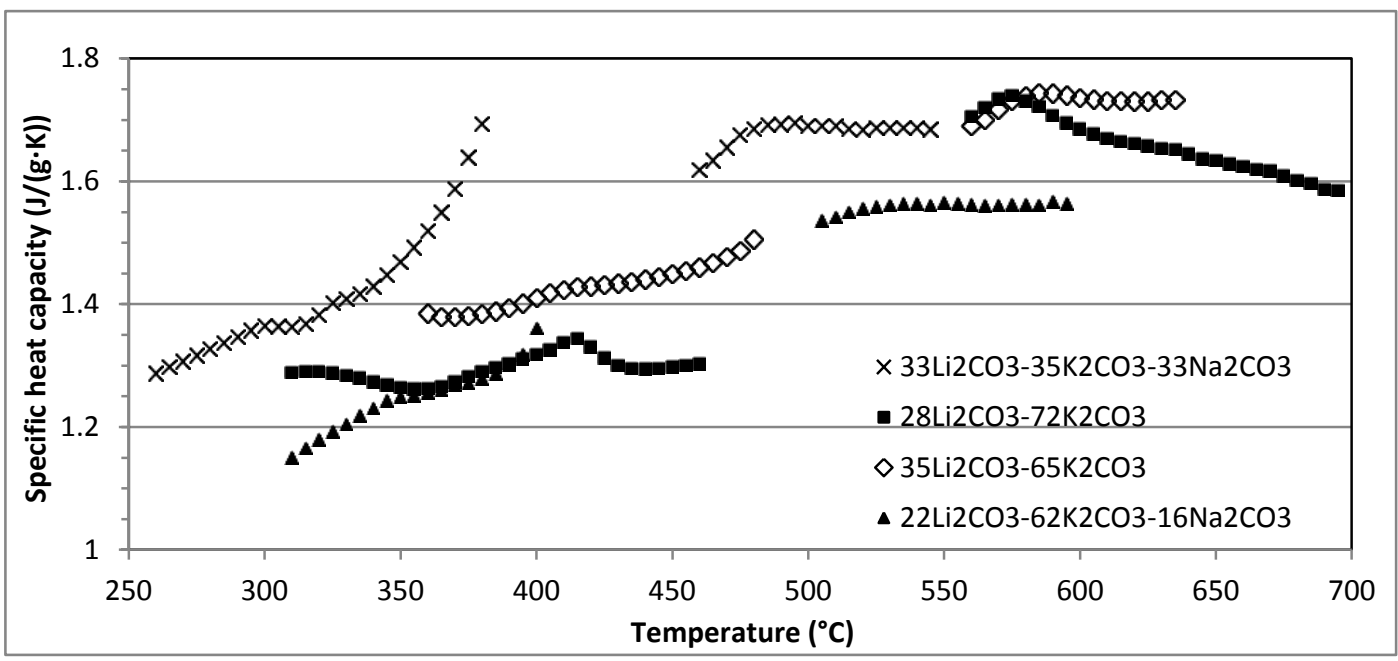



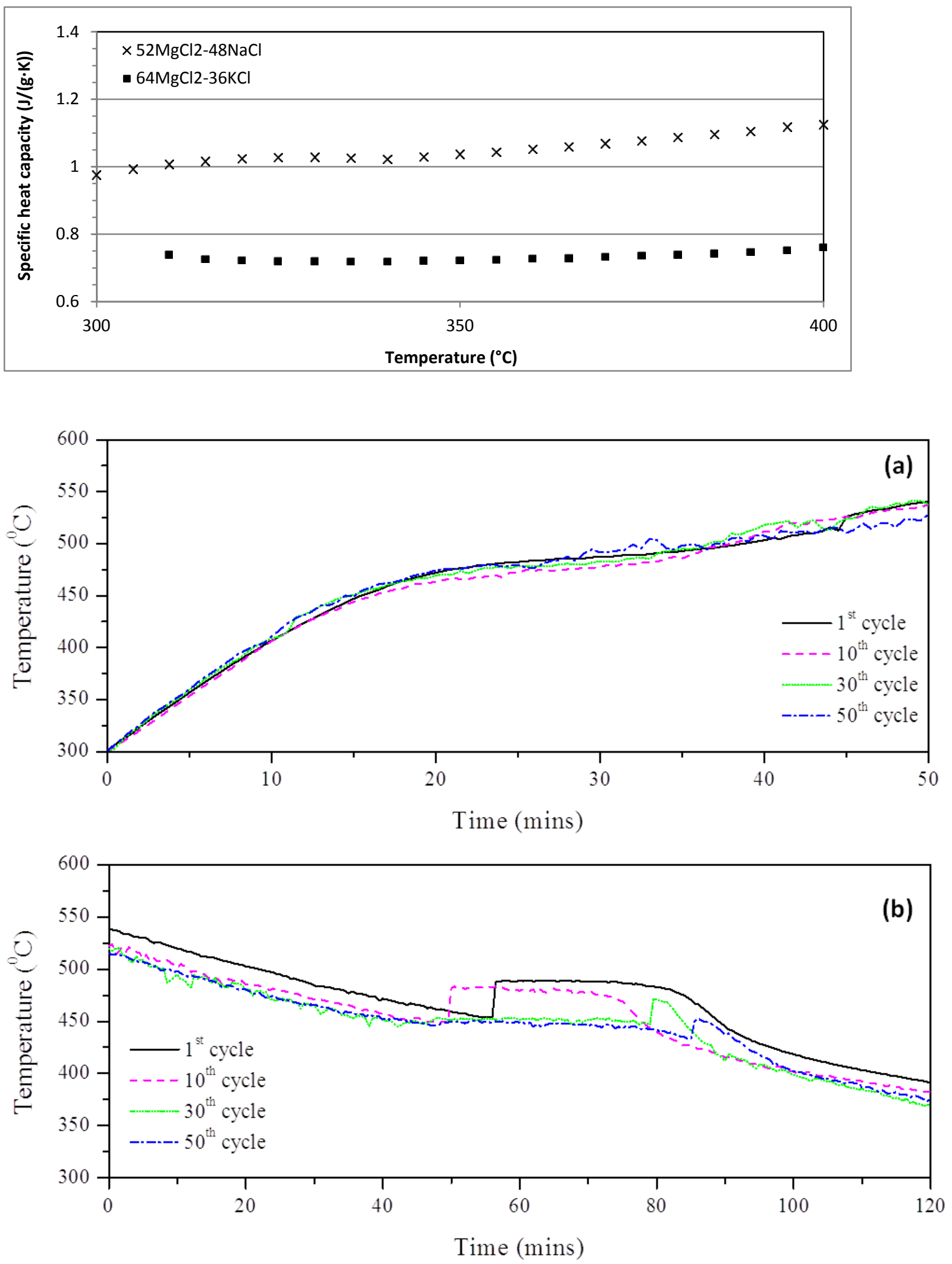


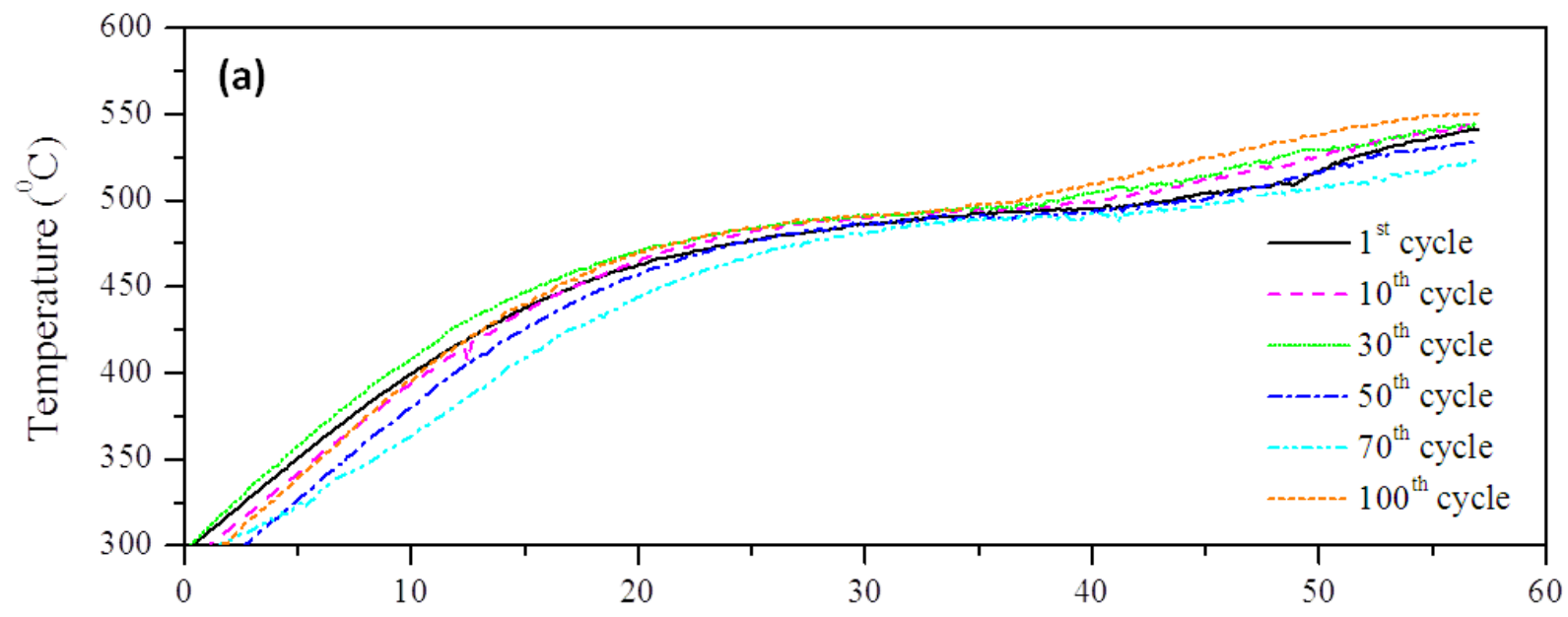

Time (mins)

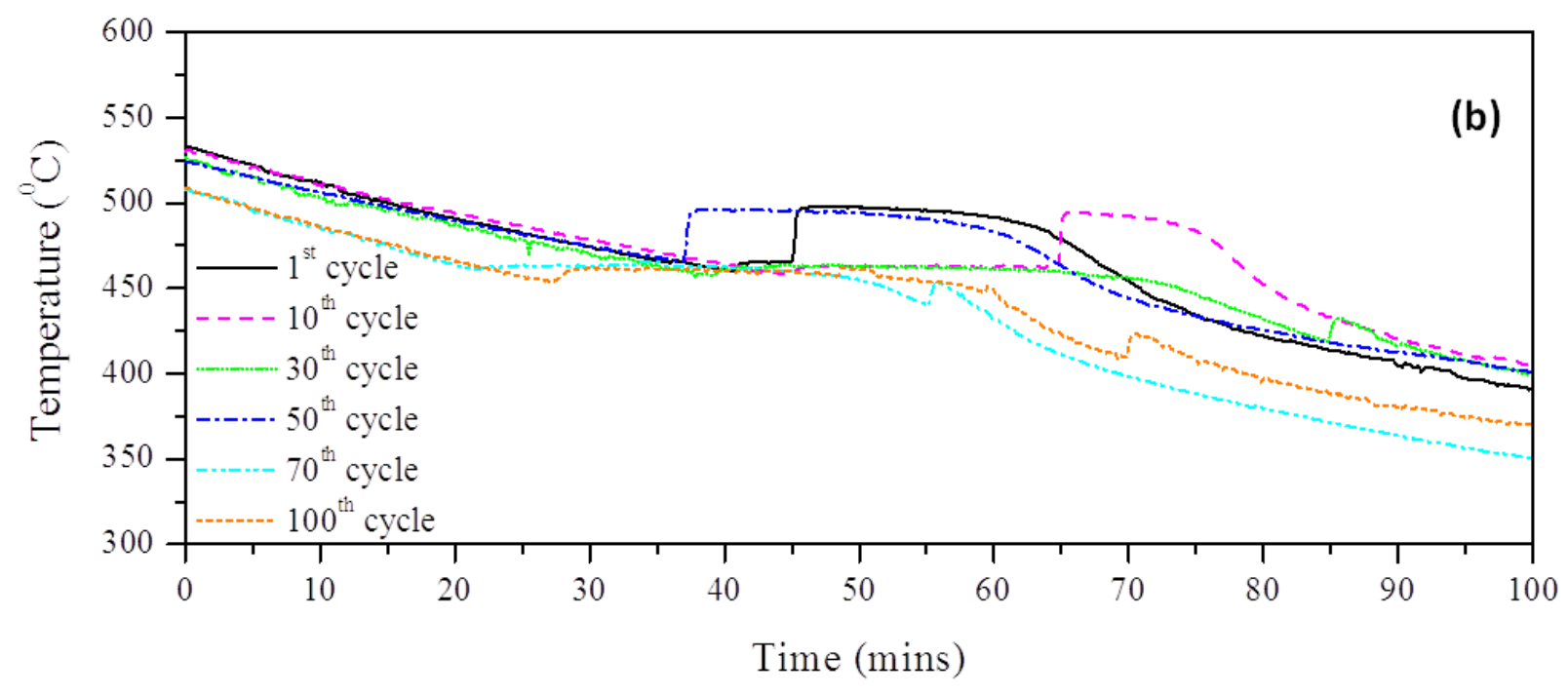



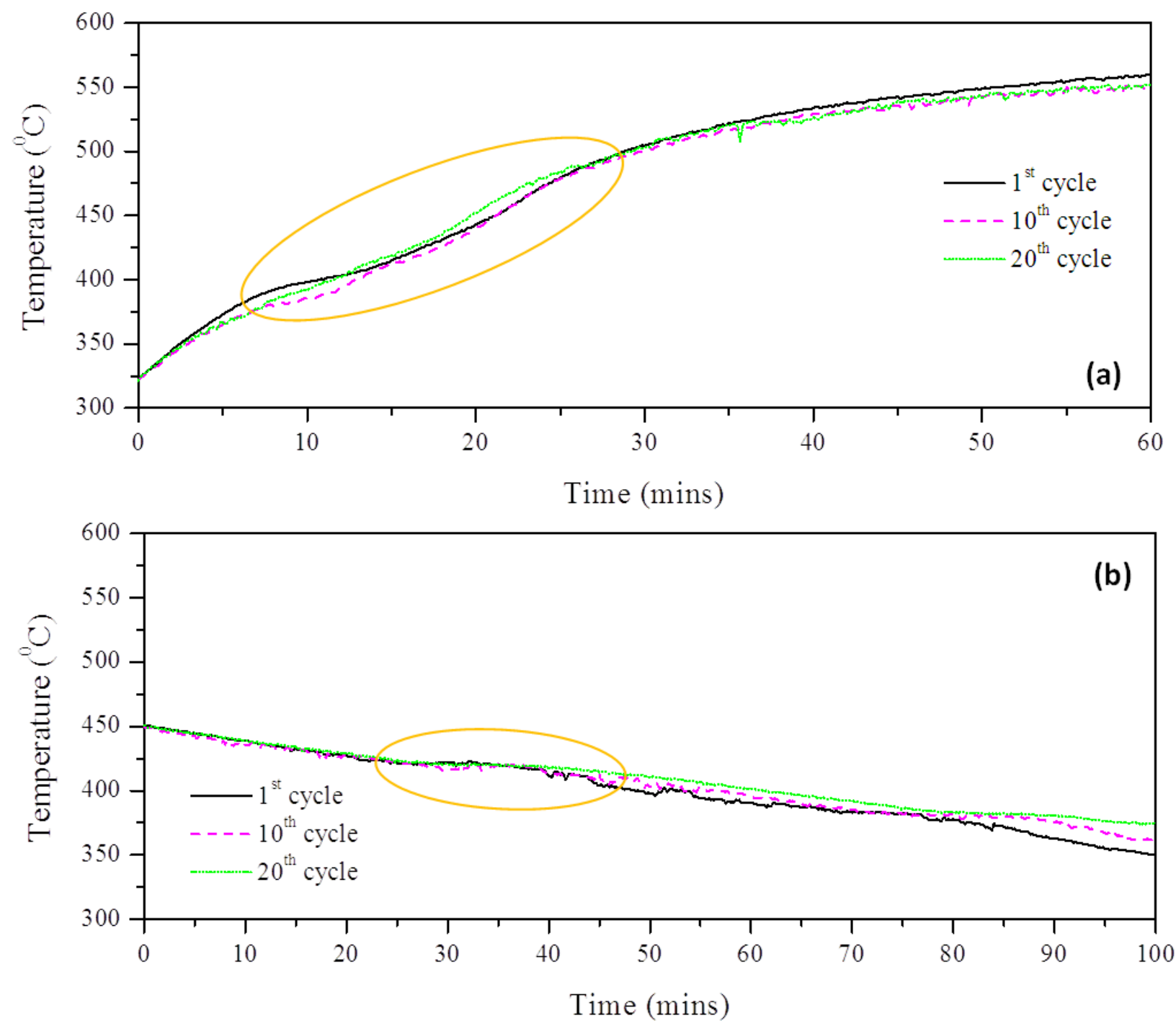


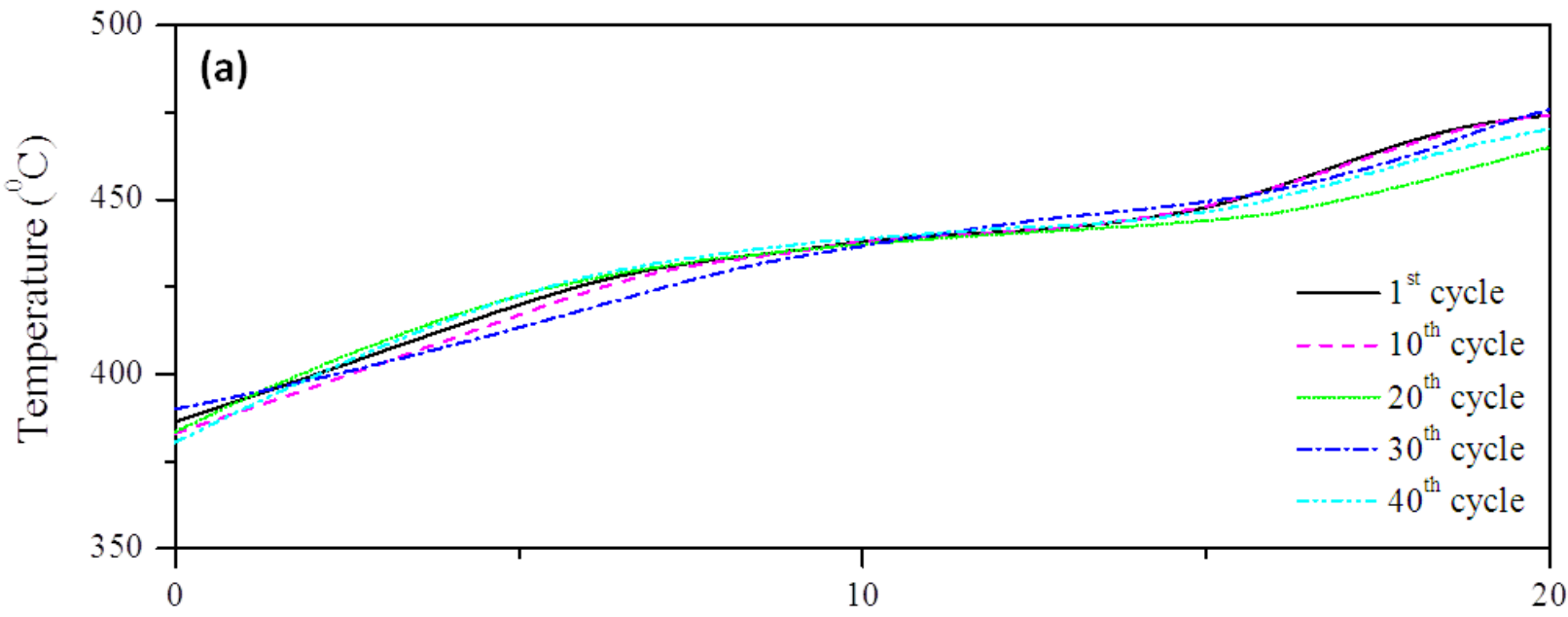

Time (mins)

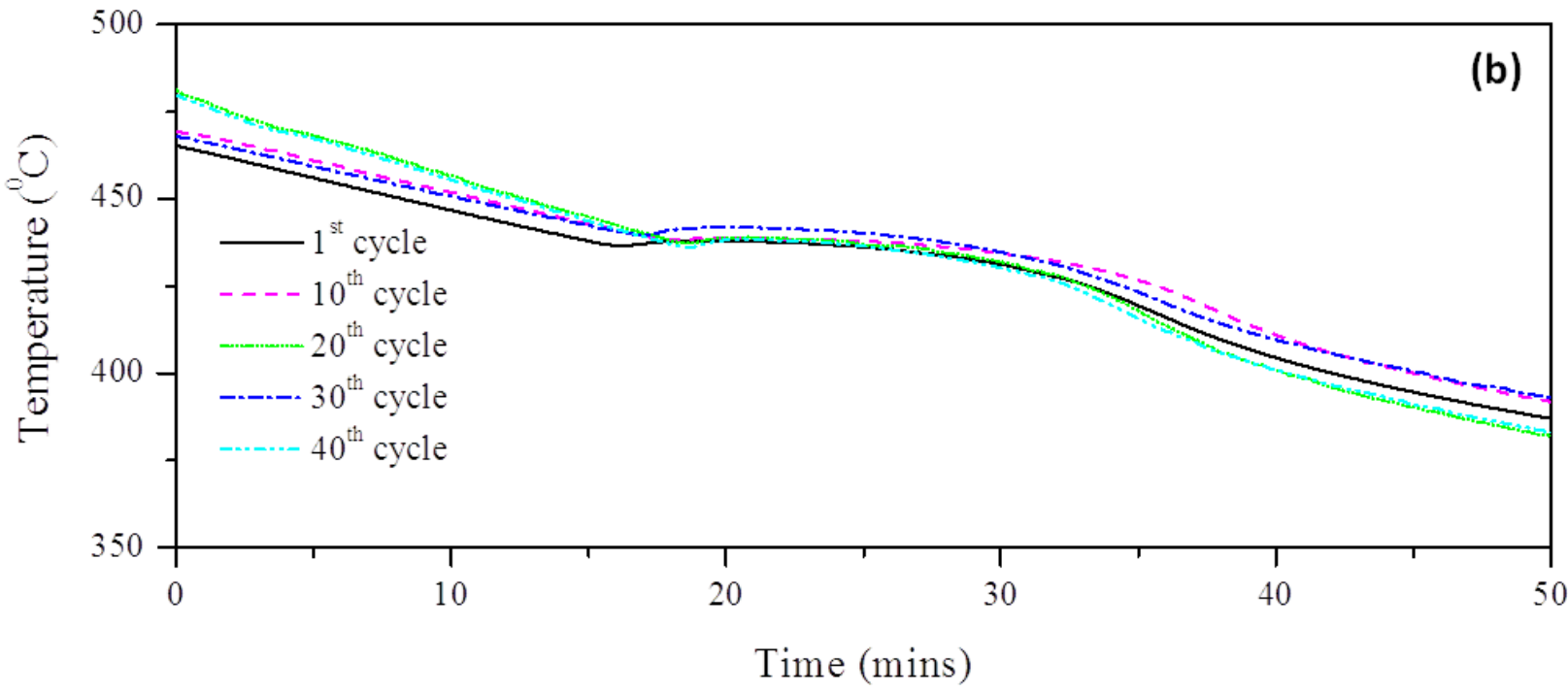

Table 4: Composition of candidate PCMs and their melting temperatures $\left(T_{m}\right)$, latent heats of fusion $(\Delta H)$, and solid and liquid specific heats $\left(C_{p, s}\right.$ and $\left.C_{p, l}\right)[15]$.

Table
$\begin{aligned} & \text { DSC } \\ & \text { DS }\end{aligned}$

5: test

results of phase-change temperature and latent heat of fusion $\left(T_{m}\right.$ and $T_{f}:$ melting and freezing temperature; $\Delta H_{m}$ and $\Delta \mathbf{H}_{\mathbf{f}}$ : latent heats of melting and freezing). 


\begin{tabular}{cl|c|c|c|c|c|c|c|}
\hline Candidate & Eutectic Composition (wt. $\%)$ & \multicolumn{1}{c}{$\begin{array}{c}\text { Weight } \\
(\mathrm{mg})\end{array}$} & $\begin{array}{c}\mathrm{T}_{\mathrm{m}} \\
\left({ }^{\circ} \mathrm{C}\right)\end{array}$ & $\begin{array}{c}\mathrm{T}_{\mathrm{f}} \\
\left({ }^{\circ} \mathrm{C}\right)\end{array}$ & $\begin{array}{c}\Delta \mathrm{H}_{\mathrm{m}} \\
(\mathrm{J} / \mathrm{g})\end{array}$ & \multicolumn{2}{c}{$\begin{array}{c}\Delta \mathrm{H}_{\mathrm{f}} \\
(\mathrm{J} / \mathrm{g})\end{array}$} & $\begin{array}{c}\text { Sub-cooling } \\
\left({ }^{\circ} \mathrm{C}\right)\end{array}$ \\
\hline $\mathrm{CA} 1$ & $\begin{array}{l}32 \mathrm{Li}_{2} \mathrm{CO}_{3}-35 \mathrm{~K}_{2} \mathrm{CO}_{3}- \\
33 \mathrm{Na}_{2} \mathrm{CO}_{3}\end{array}$ & 13.7 & 396.7 & 374.0 & 278.9 & 248.7 & 22.7 \\
\hline $\mathrm{CA} 2$ & $28.5 \mathrm{Li}_{2} \mathrm{CO}_{3}-71.5 \mathrm{~K}_{2} \mathrm{CO}_{3}$ & 11.9 & 479.9 & 440.4 & 234.3 & 233.3 & 39.5 \\
\hline $\mathrm{CA} 3$ & $35 \mathrm{Li}_{2} \mathrm{CO}_{3}-65 \mathrm{~K}_{2} \mathrm{CO}_{3}$ & 10.9 & 503.7 & 450.1 & 295.2 & 269.0 & 58.6 \\
\hline $\mathrm{CA} 4$ & $\begin{array}{l}22 \mathrm{Li}_{2} \mathrm{CO}_{3}-62 \mathrm{~K}_{2} \mathrm{CO}_{3}- \\
16 \mathrm{Na}_{2} \mathrm{CO}_{3}\end{array}$ & 14.5 & 425.5 & 412.8 & 274.7 & 211.7 & 12.7 \\
\hline $\mathrm{CH} 1$ & $52 \mathrm{MgCl}_{2}-48 \mathrm{NaCl}$ & $12.6 / 12.4 / 9.3$ & 439.1 & 430.7 & 204.2 & 190.4 & 8.4 \\
\hline $\mathrm{CH} 2$ & $64 \mathrm{MgCl}_{2}-36 \mathrm{KCl}$ & $8.3 / 15.9 / 15.7$ & 459.1 & 450.8 & 210.2 & 199.3 & 8.3 \\
\hline
\end{tabular}

Table 6: Averaged results of DSC specific heat capacities of PCM candidates $\left(C_{p, s}\right.$ and $C_{p, l}$ : solid and liquid specific heat).

\begin{tabular}{|c|c|c|c|c|c|}
\hline \multirow{2}{*}{ Candidate } & \multirow{2}{*}{$\begin{array}{c}\text { Weight } \\
(\mathrm{mg})\end{array}$} & \multicolumn{2}{c}{ Reported Values } & \multicolumn{2}{c}{ Measured Values } \\
\cline { 3 - 6 } & & $\mathrm{C}_{\mathrm{p}, \mathrm{s}}(\mathrm{J} / \mathrm{g} \cdot \mathrm{K})$ & $\mathrm{C}_{\mathrm{p}, \mathrm{l}}(\mathrm{J} / \mathrm{g} \cdot \mathrm{K})$ & $\mathrm{C}_{\mathrm{p}, \mathrm{s}}(\mathrm{J} / \mathrm{g} \cdot \mathrm{K})$ & $\mathrm{C}_{\mathrm{p}, \mathrm{l}}(\mathrm{J} / \mathrm{g} \cdot \mathrm{K})$ \\
\hline $\mathrm{CA} 1$ & 33.6 & 1.67 & 1.63 & 1.42 & 1.68 \\
\hline $\mathrm{CA} 2$ & 37.8 & - & - & 1.29 & 1.66 \\
\hline $\mathrm{CA} 3$ & 35.0 & 1.34 & 1.76 & 1.43 & 1.73 \\
\hline $\mathrm{CA} 4$ & 34.9 & 1.80 & 2.09 & 1.25 & 1.56 \\
\hline $\mathrm{CH} 1$ & 36.5 & 0.92 & 1.00 & 1.07 & - \\
\hline $\mathrm{CH} 2$ & 35.0 & 0.84 & 0.96 & 0.73 & - \\
\hline
\end{tabular}

Highlights:

- Thermo-physical properties of six candidate PCMs were measured by using DSC

- Large samples were tested in an oven subject to multiple melt-freeze cycles

- The enthalpy for melting is higher $(<20 \%)$ than that for solidification for carbonate PCMs

- $22 \mathrm{Li}_{2} \mathrm{CO}_{3}-62 \mathrm{~K}_{2} \mathrm{CO}_{3}-16 \mathrm{Na}_{2} \mathrm{CO}_{3}$ (wt.\%) is less promising as a PCM

- The phase-change enthalpies are only about half of the values in the literature for chloride PCMs 